\title{
GASTO NA SUBFUNÇÃO DESPORTO COMUNITÁRIO NA REGIÃO SUL DO BRASIL
}

\author{
SPENDING IN THE COMMUNITY SPORT SUB-HEADING IN SOUTHERN BRAZIL
}

\author{
EL GASTO EN LA SUBFUNCIÓN DEPORTE COMUNITARIO EN LA REGION SUR \\ DE BRASIL
}

\author{
Edmilson Santos Santos*, Maria José Carvalho**
}

\section{Palavras chave: Política pública. Esportes. Financiamento governamental. Descentralização.}

Keywords: Public Policy. Sports.

Financing, government. Decentralization

Palabras clave: Política pública. Deportes.

Financiación gubernamental. Descentralización.
Resumo: O presente trabalho de natureza descritiva exploratória buscou analisar de forma comparativa o comportamento dos municípios da Região Sul do Brasil no financiamento da subfunção Desporto Comunitário (sDC) de 2005 a 2014. Os recursos investidos na Função Desporto e Lazer (FDL) foram capturados junto ao site do Tesouro Nacional. A adesão e o gasto na subfunção Desporto Comunitário se deram em níveis elevados na região. Os resultados apontam também que os governos municipais são os principais financiadores desta agenda na região, quando comparados com a descentralização topdown. Os dados gerais revelam intensa atividade política na região em torno da agenda do esporte e do lazer e que, mesmo sem regulação federal, os municípios têm sido atores importantes na implementação de políticas públicas de esporte.

Abstract: This descriptive-exploratory study conducted a comparative analysis of the behavior of municipalities in the South region of Brazil when funding the Community Sport sub-heading from 2005 to 2014. Data on resources invested in the Sport and Leisure Heading were collected on the National Treasury website. Adherence to and spending on the sport community sub-heading has been high in the region. The results also indicate that municipal governments are the main funders of that agenda in the region when compared to top-down decentralization. General data reveal intense political activity around the sport and leisure agenda in the region and that municipalities have been important actors in implementing public sports policies even without federal regulation.

Resumen: Este trabajo descriptivo-exploratorio tuvo como objetivo analizar comparativamente el comportamiento de los municipios de la región sur de Brasil en la financiación de la subfunción Deporte Comunitario de 2005 a 2014. Los datos sobre los recursos invertidos en la función Deporte y Ocio se han reunido en el sitio web del Tesoro Nacional. La adhesión y el gasto en la subfunción Deporte Comunitario se han dado en niveles elevados en la región. Los resultados muestran también que los gobiernos municipales son los principales financiadores de esta agenda en la región, en comparación con la descentralización top-down. Los datos generales revelan intensa actividad política en la región en torno a la agenda del deporte y del ocio y que, incluso sin regulación federal, los municipios han sido actores importantes en la implementación de políticas públicas de deporte.
*Universidade Federal do Vale do São Francisco. Petrolina, Pernambuco, Brasil. E-mail: edmilson.santos@univasf. edu.br **Universidade do Porto. Porto Portugal. E-mail: mjc@ fade.up.pt

Recebido em: 14-01-2019 Aprovado em: 11-05-2019 Publicado em: 14-12-2019

DOI https://doi.org/10.22456/1982-8918.89583 (c) (i) () Licence 


\section{INTRODUÇÃO}

Desde o trabalho seminal de Veronez (2005), têm se avolumado análises que estão atentas ao elemento financeiro das políticas públicas. Esse movimento ganhou mais corpo nos últimos cinco anos. Surgiram muitas obras que, diretamente ou tangencialmente, colocavam a questão financeira como central à análise da atuação dos governos.

A maior parte desses trabalhos se dedica a estudar o comportamento do governo federal (FIGUERÔA; MEZZADRI; SILVA, 2014; ATHAYDE; MASCARENHAS; SALVADOR, 2015; ATHAYDE, 2016; CASTRO, 2016; CASTRO; POFFO; SOUZA, 2016; CASTRO; SCARPIN; SOUZA, 2017; MORAES et al., 2017). Recentemente têm surgido preocupações com as análises dos entes subnacionais, estados/Distrito Federal e municípios. Quanto aos estados, destacam-se Furtado et al. (2016), Diniz e Silva (2016), Silva, Santana e Silva (2015) e Vaz (2001). As análises no âmbito dos municípios têm sido realizadas através do estudo do comportamento de um dado município (VENTURIM; BORGES; SILVA, 2013; SILVA; COUTO; SANTOS, 2014; GRASSO; ISAYAMA, 2017). Santos e Hirata (2017) desenvolveram uma análise embrionária entre FDL e níveis de desenvolvimento humano.

No entanto, ainda temos uma lacuna sobre a análise da unidade orçamentária responsável por agregar os gastos nas políticas públicas municipais de esporte e de lazer, a Função Desporto e Lazer (FDL $\left.{ }^{1}\right)$. Nenhum dos trabalhos já destacado avançou no sentido de analisar o gasto na FDL ou suas subfunções, principalmente numa escala temporal mais longa (igual ou superior a dez anos), capaz de ver de forma mais clara os efeitos da descentralização engendrada pela constituição (ARRETCHE, 1996), ou seja, a capacidade dos entes subnacionais (Unidades da Federação e municípios) implementarem políticas públicas de interesse dos cidadãos.

A descentralização pode ser top-down quando a implementação da agenda é transferida de um ente superior para um ente subnacional, como acontece com o Programa Segundo Tempo. Ela é também conhecida como descentralização de cima para baixo, quando o ente subnacional aceita implementar uma agenda que não é sua. A descentralização bottomup acontece quando o ente subnacional implementa sua própria agenda, que marca sua autonomia decisória (SABATIER, 1986).

Em países federalistas, como o Brasil, é a constituição que regula o comportamento dos atores em relação à maior descentralização ou centralização das decisões. No que concerne às políticas de esporte e de lazer, a Constituição Federal de 1988 (CF/88) indicou no Art. 217 e Art. 6, respectivamente, o direito (BRASIL, 1988). No entanto, o texto constitucional não avançou no sentido de garantir competências exclusivas no âmbito da atuação dos executivos do governo federal (Art. 21 da CF/88) e do governo municipal (Art. 30 da CF/88).

Também não foram garantidas competências comuns (Art. 23 da CF/88) entre os entes federados. Aspecto esse que é fundamental para a engenharia federalista (COSTA, 2010). Assim como o governo federal, o desenho federalista não apresentou constrangimentos legais à implementação das políticas públicas de esporte e de lazer por parte dos municípios [ausência de competência no texto constitucional (BRASIL, 1988).

1 A FDL é formada por quatro subfunções: Desporto Comunitário (1); Desporto Rendimento (2); Lazer (3); Demais funções do desporto e do lazer (4). A partir de 2016, os municípios passam a registrar gastos em outra subfunção, a administrativa (5). A FDL começa a ser divulgada a partir de 2002, mas somente em 2005 por subfunção. A portaria que estabelece as funções de gasto do setor público brasileiro é a de $n^{0}$ 42, de 14 de abril de 1999 (BRASIL, 1999). 
Enquanto a descentralização bottom-up da política de esporte e de lazer promove a diversidade da política, pois cada ator tem a liberdade de escolher (preferência alocativa ${ }^{2}$ ) quando atuar, qual política deve ser implementada e o quanto investir, a descentralização bottom-up produz a diversidade da política. A descentralização top-down, nos termos colocados pela CF/88, deve garantir o que está previsto no Inciso 3 do Art. 3 da CF/88. Nesse caso, a união deve ser capaz de coordenar as ações de forma a promover maior equidade no acesso às políticas.

No âmbito do federalismo existe um vácuo institucional quando se trata de política de esporte. A maior participação dos governos municipais numa determinada agenda está diretamente relacionada ao poder de regulação que a União possui. Foi assim na descentralização da política de saúde, com o Sistema Único de Saúde, na educação, com o Fundo de Manutenção e Desenvolvimento do Ensino Fundamental e de Valorização do Magistério, e na assistência social, com a Lei Orgânica da Assistência Social. Todas normas criadas no âmbito da União acabaram regulando a participação dos municípios nas respectivas agendas (BODSTEIN, 2002; COSTA, 2010) ${ }^{3}$. Na área esportiva, ainda não temos um sistema nacional de forma a estabelecer as competências (regulação) de cada ente federado na oferta da política. Sem regulação, a inação está no horizonte do comportamento dos decisores.

A FDL tem a capacidade de regular os investimentos no esporte em apenas duas manifestações esportivas: esporte participação [subfunção Desporto Comunitário (sDC)] e esporte rendimento. Reconhecendo o desporto comunitário como um importante elemento da formação esportiva da sociedade, torna-se importante e relevante conhecer o comprometimento dos governos locais da Região Sul com essa agenda, o gasto na SDC.

Nesse sentido, o presente trabalho buscou analisar de forma comparativa 0 comportamento dos municípios da Região Sul do Brasil no financiamento da SDC, de 2005 a 2014. Como objetivos específicos o estudo buscou investigar: (1) o nível de adesão dos municípios ao gasto na SDC; (2) a média e desvio padrão de gasto na FDL comprometido com a sDC por unidade da federação da Região Sul; (3) a evolução do gasto na SDC; (4) comparar a descentralização top-down e bottom-up das políticas de esporte e lazer para o período entre 2005 e 2011.

\section{METODOLOGIA}

Este trabalho de natureza descritiva exploratória buscou analisar de forma comparativa o comportamento dos municípios da Região Sul do Brasil no financiamento da sDC4 durante os dez primeiros anos de sua implementação. A divulgação dos dados referentes às subfunções que a Secretaria do Tesouro Nacional disponibilizou, no Sistema de Informações Contábeis e Fiscais do Setor Público Brasileiro (SICONFI), inicia a partir de 2005. Sendo assim, o estudo buscou acompanhar os dez primeiros anos de registro do gasto por subfunção (2005 a 2014).

Os dados referentes à FDL foram coletados diretamente no site do SICONFI (http:// www.tesouro.fazenda.gov.br/pt PT/contas-anuais) ${ }^{5}$ entre os dias 3 e 8 de novembro de 2017.

\footnotetext{
2 Utilizamos o conceito de preferência alocativa (em alguns momentos no texto ele pode aparecer de forma simplificada, como apenas "preferência") utilizado por Rezende (1997).

3 Em alguns casos, a interpretação pode se dar pelo viés do comprometimento dos municípios com os temas de interesse local (RIBEIRO, 2013). Mas sua maior responsividade está associada ao comportamento dos legislativos municipais (Inciso 1 do Art. 30 da CF/88).

4 Não há orientação por parte do Tesouro Nacional sobre quais ações devem ser realizadas no desporto comunitário. No entanto, cada gestor municipal, a seu modo, estabelece um nível de distinção entre o que deve ser considerado desporto comunitário e desporto rendimento.

5 Para os dados superior a 2012: https://siconfi.tesouro.gov.br/siconfi/pages/public/consulta finbra/finbra list.jsf
} 
A listagem dos municípios foi buscada diretamente no site do Instituto Brasileiro de Geografia e Estatística (IBGE, 2006). A elaboração de uma planilha Excel permitiu concentrar as informações do gasto na FDL e da SDC de todos os municípios da Região Sul. Para efeitos deste trabalho, consideramos apenas os recursos liquidados, na medida em que eles se referem à execução do serviço [regulada pelo Art. 63 da Lei no. 4.320/1964 (BRASIL, 1964)].

A estatística descritiva foi utilizada para verificar a média e o desvio padrão. Para garantir a comparabilidade das informações fiscais, os valores referentes à FDL e às transferências do governo federal, foram deflacionados pelo Índice de Preços ao Consumidor (IPCA) para o ano de 2005 a 2014 para todos os municípios e 2005 a 2011 para comparabilidade das políticas bottom-up [análise I] e top-down x bottom-up [análise II: governo federal para municípios].

Para a análise I foi elaborada uma planilha Excel contendo as informações referentes aos municípios da Região Sul por estado, população, gasto na FDL e subfunções de 2005 a 2014. Para a análise II, foi elaborada uma planilha Excel contendo os gastos na FDL de 2005 a 2011 e os gastos da descentralização top-down dos dois programas mais importantes da agenda social do Ministério do Esporte, no que se refere ao custo de implementação das ações pelos municípios ${ }^{6}$ : Segundo Tempo (PST) e Esporte e Lazer da Cidade (PELC). Para o Ministério do Esporte, os dois programas são registrados na subfunção Desporto Comunitário7. A escolha do intervalo da análise II se deve à existência de dados já consolidados sobre 0 gasto liquidado dos programas PELC e PST para os estados da Região Sul compilados do trabalho de Castro (2016).

O nível de adesão visa identificar a preferência alocativa aferindo o percentual de municípios que se comprometeram com uma determinada agenda de gasto. Para efeito deste trabalho, estabelecemos quatro níveis de adesão: inação [0\% de adesão]; nível baixo, quando a adesão se deu superior a $0,1 \%$ e igual ou inferior a $50 \%$; nível médio, quando a adesão se deu acima de $50 \%$ e igual ou inferior a $80 \%$; nível alto, quando a adesão se deu acima de $80 \%$.

\section{ANÁLISE DOS RESULTADOS}

Preliminarmente, é importante analisar qual tem sido o comportamento dos municípios na Região Sul quanto ao gasto na FDL. Como revela a Tabela 1, o grau de adesão dos municípios ao gasto na FDL se manteve alto em quase toda a década, apesar da forte queda em 2014. O resultado indica que a participação dos municípios promove um comportamento que difere daquele expresso nas regras de nosso federalismo. A inação foi minoritária em todo o período considerando a adesão ano a ano, e apenas oito cidades, todas do Rio Grande do Sul (RS), tiveram esse comportamento durante todo o período. A inexistência de regulação federal não tem impedido que municípios invistam em políticas de esporte via FDL.

Mesmo não tendo nenhuma obrigação objetiva de investir recursos na FDL, os municípios preferem realizar gastos nessa agenda e ela se deu em patamares elevados (nível alto) para todo o período. As motivações estão além dos limites deste trabalho, mas apontam a existência de variáveis importantes pressionando a agenda de gasto dos municípios em direção às políticas de esporte e de lazer como a estrutura da burocracia, os ciclos políticos-eleitoral, a estrutura administrativa (SANTOS; STAREPRAVO, 2018) ou a existência de normas no âmbito dos municípios que regulem o comportamentos dos atores, por exemplo. 
Tabela 1 - Nível de adesão dos municípios da Região Sul ao gasto na FDL de 2005 a 2014 (\%).

\begin{tabular}{lllllllllll}
\hline UF & $\mathbf{2 0 0 5}$ & $\mathbf{2 0 0 6}$ & $\mathbf{2 0 0 7}$ & $\mathbf{2 0 0 8}$ & $\mathbf{2 0 0 9}$ & $\mathbf{2 0 1 0}$ & $\mathbf{2 0 1 1}$ & $\mathbf{2 0 1 2}$ & $\mathbf{2 0 1 3}$ & $\mathbf{2 0 1 4}$ \\
\hline PR & $\mathbf{9 2 , 9 8}$ & $\mathbf{9 6 , 9 9}$ & 95,49 & 95,74 & 96,24 & 96,74 & 97,49 & 96,24 & 94,49 & 86,72 \\
RS & 96,20 & 91,75 & 92,35 & 92,15 & 93,16 & 92,96 & 93,56 & 94,37 & 95,57 & 86,32 \\
SC & 94,92 & 96,61 & 95,93 & 97,29 & 96,61 & 96,95 & 96,61 & 96,61 & 96,95 & 84,41 \\
\hline
\end{tabular}

Fonte: Dados da pesquisa.

Quando analisamos o nível de adesão ao gasto na sDC (Tabela 2), é possível perceber que a participação dos municípios da Região Sul foi acima de $77,48 \%$, resultado encontrado em 2005, no RS. Nos outros cenários os resultados indicam alta adesão ao gasto na sDC. Ou seja, é uma das agendas que recebe forte atenção dos policy makers locais (decisores locais: prefeito ou secretários). Importante salientar que a adesão às subfunções não se dá de forma a eliminar a participação de outra. Elas podem se dar de forma simultânea. Portanto, nesse nível de análise, não é possível identificar preferências alocativas no âmbito da adesão.

Considerando o percentual de adesão na região, não é possível estabelecer grandes distinções de comportamento. Alguns resultados chamam atenção: (a) em todos os cenários o nível de participação dos municípios dos estados do Paraná (PR) e de Santa Catarina (SC) foi alto. Esse resultado indica que há fortes estímulos no estado que pressionam essa agenda; (b) o RS obteve nível alto de adesão em $60 \%$ do período e SC em 100\%; (c) apesar de apresentar alto nível de adesão, o PR não conseguiu ultrapassar a casa dos 90\%.

Apesar da variação em termos de adesão ao longo do tempo e entre os estados da Região Sul, é possível perceber que a sDC tem recebido atenção dos policy makers. 0 desporto comunitário é uma agenda importante nesta região, como indica a Tabela 2, pois em apenas um cenário foi alcançado o nível médio de adesão (RS/2005).

Tabela 2 - Nível de adesão dos municípios da Região Sul à subfunção Desporto Comunitário de 2005 a 2014 (\%).

\begin{tabular}{lllllllllll}
\hline UF & $\mathbf{2 0 0 5}$ & $\mathbf{2 0 0 6}$ & $\mathbf{2 0 0 7}$ & $\mathbf{2 0 0 8}$ & $\mathbf{2 0 0 9}$ & $\mathbf{2 0 1 0}$ & $\mathbf{2 0 1 1}$ & $\mathbf{2 0 1 2}$ & $\mathbf{2 0 1 3}$ & $\mathbf{2 0 1 4}$ \\
\hline PR & 89,22 & 85,01 & 85,30 & 85,60 & 85,16 & 86,79 & 88,43 & 88,28 & 88,33 & 87,57 \\
RS & 77,48 & 87,72 & 88,67 & 91,05 & 89,42 & 93,29 & 94,62 & 92,96 & 93,26 & 92,54 \\
SC & 93,93 & 91,23 & 94,35 & 93,38 & 93,33 & 94,76 & 95,79 & 96,14 & 95,10 & 95,18 \\
\hline
\end{tabular}

Fonte: Dados da pesquisa.

O primeiro aspecto a ser analisado na Tabela 3 é que para todos os estados da Região Sul a média de gasto na sDC é próxima ou superior a $90 \%$. Além de demonstrar a importância da agenda frente aos gastos na FDL, ele indica uma distinção no comportamento do PR e do RS.

O nível de adesão à sDC no PR nunca chegou a 90\%, no entanto a média de gasto foi sempre superior. A menor adesão não indica que os valores aportados nesta agenda não sejam elevados. Apesar de menor adesão há uma maior preferência de gasto na subfunção. No RS, em 70\% do período, o gasto foi inferior ao nível de adesão.

Os dados permitem observar também que o RS tem a maior variação em termos de gasto. Ele apresenta o maior desvio padrão em todo o período. Os estados do PR e de SC têm comportamentos similares. Essa variação é compatível com os resultados da descentralização bottom-up. As distinções não representam alguma anomalia, mas uma característica central do 
federalismo. O mais importante a constatar é que a atenção nesta agenda é elevada nas duas direções, da adesão e do recurso.

Tabela 3 - Média e desvio padrão (DP) do percentual de gasto do gasto na FDL comprometido com a SDC por estado da Região Sul.

\begin{tabular}{cccccccccccc}
\hline UF & & $\mathbf{2 0 0 5}$ & $\mathbf{2 0 0 6}$ & $\mathbf{2 0 0 7}$ & $\mathbf{2 0 0 8}$ & $\mathbf{2 0 0 9}$ & $\mathbf{2 0 1 0}$ & $\mathbf{2 0 1 1}$ & $\mathbf{2 0 1 2}$ & $\mathbf{2 0 1 3}$ & $\mathbf{2 0 1 4}$ \\
\hline \multirow{3}{*}{ PR } & $\mathrm{n}$ & 331 & 229 & 325 & 327 & 327 & 335 & 344 & 339 & 333 & 303 \\
& MMédia & 94,47 & 94,76 & 95,85 & 93,67 & 94,88 & 94,64 & 93,83 & 93,99 & 93,05 & 93,19 \\
& $\mathrm{DP}$ & 16,74 & 15,86 & 13,54 & 17,97 & 16,47 & 15,37 & 17,48 & 17,2 & 19,39 & 19,76 \\
\hline \multirow{2}{*}{ RS } & $\mathrm{n}$ & 382 & 400 & 407 & 417 & 414 & 417 & 417 & 417 & 417 & 397 \\
& MMédia & 90,5 & 90,08 & 89,46 & 87,46 & 88,94 & 89,13 & 87,84 & 87,88 & 89,76 & 88,67 \\
& DP & 23,01 & 22,29 & 23,93 & 26,13 & 24,74 & 23,61 & 25,77 & 25,74 & 23,79 & 24,57 \\
\hline \multirow{2}{*}{ SC } & $\mathrm{n}$ & 263 & 260 & 267 & 268 & 266 & 271 & 213 & 274 & 272 & 237 \\
& MMédia & 95,38 & 93,75 & 93,42 & 94,84 & 94,7 & 94,16 & 93 & 92 & 94,64 & 92,56 \\
& DP & 16,56 & 19,67 & 19,2 & 17,41 & 16,28 & 16,93 & 19,7 & 21,44 & 16,88 & 19,86 \\
\hline
\end{tabular}

Fonte: Dados da pesquisa.

Como pode ser observado na Tabela 4, no período houve distintas evoluções nos gastos na FDL e na sDC. Em nenhum estado foi possível observar crescimento ou decréscimo de investimento durante todo o período.

Ao longo do período todos os estados tiveram crescimento no investimento considerando os dez anos. No PR, a evolução foi de 41,6\% [R \$ 95,5 milhões para R\$135,2 milhões], no RS, 59,5\% [R \$ 59,7 milhões para $\mathrm{R} \$ 95,2$ milhões], e, em SC, 99,2\% [R $\$ 77,5$ milhões para R\$154,4 milhões]. Ou seja, o crescimento do gasto na FDL no estado de SC foi o maior da região.

Mesmo não ocorrendo na mesma intensidade, o comportamento dos estados seguiu o padrão encontrado na FDL: no PR a evolução foi de $22 \%$ [R \$ 62,2 milhões para $\mathrm{R} \$ 75,9$ milhões], no RS, 56,6\% [R \$ 37,1 milhões para R \$ 58,1 milhões] e, em SC, 81,8\% [R \$ 58,3 milhões para $\mathrm{R} \$ 106$ milhões]. Somente nos anos de 2008, 2010 e 2011 houve crescimento positivo para a FDL e sDC em todos os estados da Região Sul. Os anos de maiores quedas nos investimentos foram 2009, 2014 e 2012.

$O$ resultado mais importante da Tabela 4, quando comparado especialmente com as Tabelas 1 e 2, é que os recursos têm se ampliado acima da variação dos níveis de adesão da FDL e da SDC. Ou seja, houve um crescimento sólido do volume de recursos destinados à sDC ao longo dos dez anos. As distinções são compatíveis com o federalismo.

Tabela 4 - Evolução dos gastos na FDL e subfunção Desporto Comunitário.

\begin{tabular}{cccccccccccc}
\hline UF & GGasto & 2005 & 2006 & $\mathbf{2 0 0 7}$ & $\mathbf{2 0 0 8}$ & $\mathbf{2 0 0 9}$ & $\mathbf{2 0 1 0}$ & $\mathbf{2 0 1 1}$ & $\mathbf{2 0 1 2}$ & $\mathbf{2 0 1 3}$ & $\mathbf{2 0 1 4}$ \\
\hline \multirow{2}{*}{ PR } & FDL & - & 31,2 & $-2,3$ & 22 & $-9,4$ & 4,8 & 16,6 & 9,9 & $-27,1$ & 2,1 \\
& DC & - & 18,5 & 7,9 & 21,4 & $-10,4$ & 7,1 & 17,1 & 9,4 & $-23,1$ & $-16,8$ \\
\hline \multirow{2}{*}{ RS } & FDL & - & 15,4 & 21,5 & 22,6 & $-13,5$ & 13,2 & 19,4 & $-4,6$ & $-21,9$ & 6,5 \\
& DC & - & 64 & 6,4 & 27,2 & $-20,1$ & 20,4 & 25,9 & $-5,4$ & $-21,5$ & $-4,1$ \\
\hline \multirow{2}{*}{ SC } & FDL & - & 16,3 & 2,9 & 32,9 & $-11,8$ & 34,8 & 8,7 & $-3,1$ & 18,5 & $-15,6$ \\
& DC & - & $-11,5$ & 12 & 53,3 & $-15,7$ & 35,1 & 7,5 & $-2,3$ & 18,1 & $-15,3$ \\
\hline \multicolumn{7}{c}{ Fonte: Dados da pesquisa. }
\end{tabular}


A análise comparativa entre os comportamentos top-down e bottom-up na agenda esportiva permite observar com maior nitidez a participação dos entes federados, especialmente, aqui, os governos central e local, na descentralização do desporto comunitário (participação). Como observado até aqui, o comportamento dos municípios segue o previsto na descentralização bottom-up, principalmente para uma agenda não regulada por legislação federal. Diversidade pode significar desigualdade, e é nesse aspecto que se torna importante a participação do governo central.

A primeira observação é que tanto municípios como o governo central realizaram investimentos na Região Sul no período aqui analisado (Tabela 5). Outro fator é que o estado que mais absorveu recursos do governo central, quando comparado com aqueles investidos pelos próprios municípios (descentralização bottom-up), foi o RS.

Como pode ser observado na Tabela 5, o menor percentual foi 13\% em 2005 e o maior $36,4 \%$ em 2009. Santa Catarina é o que menos recebe recursos quando comparado com a produção de seus municípios nesta área. Em todo o período os menores volumes de captação de recursos top-down foram do estado e os recursos bottom-up permaneceram elevados garantindo menor peso dos recursos federais na oferta da política de esporte e de lazer. A menor propensão do estado receber recursos destoa do comportamento dos outros estados da região. Ou seja, há um efeito local da implementação dos programas federais que precisava ser mais bem compreendido.

Tabela 5 - Participação do PELC/PST na descentralização top-down (TD) de investimentos da Região Sul comparado com a descentralização bottom-up (BU) (R\$ e por milhão).

\begin{tabular}{|c|c|c|c|c|c|c|c|c|}
\hline UF & Unidade & 2005 & 2006 & 2007 & 2008 & 2009 & 2010 & 2011 \\
\hline \multirow{3}{*}{ PR } & $\mathrm{TD}^{*}$ & 12,3 & 12,6 & 21,7 & 21,8 & 18,7 & 15,8 & 12,1 \\
\hline & $\mathrm{BU}$ & 95,5 & 125,3 & 122,4 & 149,3 & 135,2 & 141,7 & 165,2 \\
\hline & $\%$ & 12,9 & 10,0 & 17,7 & 14,6 & 13,8 & 11,1 & 7,3 \\
\hline \multirow{3}{*}{ RS } & $\mathrm{TD}^{*}$ & 7,8 & 13,0 & 16,4 & 29,5 & 32,3 & 22,0 & 23,8 \\
\hline & $\mathrm{BU}$ & 59,7 & 68,9 & 83,7 & 102,6 & 88,8 & 100,5 & 120,0 \\
\hline & $\%$ & 13,0 & 18,9 & 19,6 & 28,8 & 36,4 & 21,9 & 19,9 \\
\hline \multirow{3}{*}{ SC } & $T D^{*}$ & 1,7 & 2,9 & 3,7 & 7,0 & 6,5 & 4,2 & 3,2 \\
\hline & $\mathrm{BU}$ & 77,5 & 90,1 & 92,7 & 123,2 & 108,7 & 146,5 & 159,3 \\
\hline & $\%$ & 2,2 & 3,2 & 4,0 & 5,7 & 6,0 & 2,8 & 2,0 \\
\hline \multirow{3}{*}{ Total } & TD & 21,8 & 28,5 & 41,8 & 58,3 & 57,5 & 42 & 39,1 \\
\hline & $\mathrm{BU}$ & 232,7 & 284,3 & 298,8 & 375,1 & 332,7 & 388,7 & 444,5 \\
\hline & $\% \mathrm{TU}$ & 8,6 & 9,1 & 12,3 & 13,5 & 14,7 & 9,8 & 8,1 \\
\hline
\end{tabular}

\section{DISCUSSÃO DOS RESULTADOS}

A pouca atenção da policy community (comunidade de especialistas no tema) ao gasto dos municípios com a FDL destoa da importância desempenhada por eles à maior democratização do esporte e do lazer no Brasil e cria dificuldades comparativas, dado que a esfera municipal possui 5.570 entes.

Como podemos observar nos resultados aqui apresentados, há intensa participação dos municípios da Região Sul no gasto na FDL sem que haja regulação federal para justificar 
tal resultado, na medida em que não aparece entre as competências dos governos municipais à implementação de políticas de esporte (Art. 30 da CF/88). Em outras áreas, isso só foi possível por conta da capacidade de coordenação da União (BODSTEIN, 2002; COSTA, 2010). Até 0 presente momento, o Brasil não conseguiu avançar no sentido de criar um sistema esportivo que estabelecesse as competências de cada ente federado na oferta do esporte e do lazer. Por diferentes motivos, como Souza (2006), certas ideias têm dificuldades de penetrar na agenda decisória.

Isso significa que a inexistência de uma norma específica no âmbito da federação determinando a necessidade de os municípios implementarem políticas de esporte, como acontece com a educação e a saúde, não tem impedido que decisões políticas sejam tomadas na esfera local (descentralização bottom-up) e que garantam a implementação das políticas de esporte. Contrariando os incentivos do federalismo [a inexistência de competências privativas no âmbito dos executivos municipais à implementação de políticas de esporte e de lazer (Art. $30 \mathrm{CF} / 88$ ], os municípios têm participado da descentralização das políticas de esporte de forma efetiva. Resta compreender as variáveis que afetam esse resultado. No caso do estado do Piauí, Santos e Starepravo (2018) identificaram que a estrutura administrativa, ter ou não secretaria (exclusiva ou não), não impacta na decisão de alocar recursos na FDL. Outras variáveis precisam ser testadas, como a existência de normas locais (implementação do Art. 24 da CF/88) que poderiam estar pressionando por esse resultado.

Diante das competências estabelecidas na CF/88, a hipótese mais razoável, diante das características do federalismo brasileiro, é a inação. No entanto, mesmo antes de se iniciarem os registros de gastos nas políticas de esporte e de lazer (em 2002), já havia experiências administrativas municipais implementando essas políticas. Nesse caso, esses achados abrem espaço para a possibilidade de interpretar essa manutenção da agenda ao longo do tempo nos termos propostos pela path dependence [para essa análise, ver Bernardi (2012)]. De forma resumida, a path dependence indica que há fatores institucionais que criam constrangimentos a uma decisão que quebre a trajetória. Os custos políticos não compensariam uma mudança.

Os resultados em termos de adesão ao gasto na FDL são forte indicativo de que na área esportiva há outras variáveis intervenientes que pressionam por esse resultado e que essa agenda goza de forte reconhecimento por parte da sociedade. Considerando que cumpre aos municípios implementarem políticas de interesse local, o gasto na FDL demonstra que esse interesse local se faz presente na área esportiva, mesmo sem regulação federal.

Dentre as características da descentralização bottom-up está a diversidade de políticas e de recursos investidos. Cada governo tem legitimidade para impor a essa agenda a política que responda às necessidades políticas e sociais de sua administração. Nesse sentido, não cabe olhar para a inação como uma desresponsabilização, pois o direito (Art. 6 e Art. 217 da CF/88) poderia ser ofertado por outro ente federal. A inação de um não significa necessariamente a inação dos outros entes federados. A não oferta de políticas de esporte e de lazer de um município não significa, necessariamente, que o estado ou a União não possam estar investindo nessas áreas, nesses municípios.

Parte importante da literatura sobre políticas públicas de esporte e de lazer tem se debruçado sobre o papel desempenhado pela União. Não raro os estudos críticos apontam que o governo federal prioriza gastos no desporto rendimento (CARNEIRO, 2018). Muitas vezes, de forma equivocada, interpretam o papel do governo federal como se ele representasse o próprio 
Estado (MASCARENHAS, 2016) ${ }^{8}$. Essas são afirmações que não poderiam ser realizadas sem levar em consideração os dispositivos constitucionais sobre as competências exclusivas e comuns do governo federal e sobre o desenho federalista brasileiro para implementação de políticas de esporte. A constituição não estabeleceu competências na área esportiva ao governo federal e nem ele responde de forma solitária pelo Estado. Portanto, o que acontece nos municípios em termos de adesão e de recursos investidos dá uma outra conotação no debate sobre a democratização do esporte e do lazer no Brasil.

Como podemos observar ao longo do trabalho, há nível alto de descentralização bottomup das políticas de esporte e de lazer nos municípios dos três estados da Região Sul. Por outro lado, analisando exclusivamente o comportamento do governo federal, há importantes investimentos na região e uma menor participação desses investimentos no estado de SC.

O nível alto de adesão na sDC e os investimentos nela realizados significam que os municípios da Região Sul preferem realizar gasto no desporto comunitário a realizá-lo no desporto rendimento, como identificou a Tabela 3. Considerando os resultados da SDC aqui apresentados, isso coloca o município como um investidor importante do esporte participação (esporte comunitário) e um investidor minoritário no esporte rendimento (em todos os estados a maior parte do gasto na FDL se dá na SDC). A inexistência de estudos sobre a participação dos municípios no financiamento da subfunção Desporto Rendimento dificulta uma análise mais aprofundada do tema.

Apesar de encontramos distintos comportamentos na capacidade de gasto dos municípios na SDC por estado, parece que em dois momentos específicos houve efeito de variáveis regionais (ou nacional) pressionando pela redução dos investimentos. Em 2008 e em 2014, todos os estados tiveram retração de recursos quando comparados com o ano anterior. Em 2008, a diminuição dos investimentos na subfunção pode estar associada à diminuição no gasto total na FDL. Em todos os estados houve redução da FDL e da subfunção (PR: FDL/9,44\% e sDC/-10,44\%; RS: FDL/13,48\% e sDc-20,04\%; SC: FDL/-11,78\% e sDC - 15,63\%).

Tanto governo federal como os municípios podem atuar de forma independente ou de forma cooperada para o desenvolvimento das políticas públicas de esporte e de lazer. Sendo assim, foi possível confrontar dois modelos de descentralização, a descentralização top-down, do governo federal [2005 a 2011 (CASTRO, 2016)], e a descentralização bottom-up, dos municípios, na Região Sul do Brasil. Os resultados, para os níveis de análise aqui propostos, dão conta de que o volume de recursos não indica sua concentração em áreas com níveis elevados de desenvolvimento econômico e social. Esse é um aspecto positivo se considerarmos a função constitucional do governo federal quanto à diminuição das desigualdades regionais.

Em todos os cenários, o percentual de gasto na FDL é muito superior à descentralização top-down para os dois programas aqui apresentados, demonstrando de forma muito clara que o município é um player importante no gasto em políticas públicas de esporte e de lazer (Tabela 5). Em cinco cenários, o gasto na subfunção é superior a 1000\% do gasto do governo federal com os dois programas. Os menores percentuais foram encontrados no RS, mesmo assim com valores elevados. No estado de SC, a participação do governo federal foi muita mais tímida, quando comparado com os outros estados.

8 Athayde et al. (2016) fazem uma revisão das legislações sobre o direito ao esporte focando exclusivamente o comportamento do governo federal, mas existe um campo normativo vasto (legislativos estaduais e do Distrito Federal e dos 5.570 municípios) que não pode ser desconsiderado quando se quer analisar o direito ao esporte no Estado brasileiro. Nenhum ente isoladamente responde em nome do Estado. 
Apesar de não ser o foco principal deste trabalho, a comparação entre as políticas topdown e bottom-up na Região Sul denuncia diferenciações na distribuição alocativa da política pública. Tendo os municípios da Região Sul capacidade de investimento em políticas públicas de esporte e de lazer, qual o sentido de alocar recursos escassos do governo federal na região em detrimento das regiões Norte e Nordeste?

\section{CONCLUSÃO}

0 presente trabalho buscou analisar de forma comparativa o comportamento dos municípios da Região Sul do Brasil no financiamento da sDC. Quanto a esse aspecto, o estudo identificou que:

Nível de adesão na sDC: para quase todos os cenários a adesão ao desporto comunitário se deu em níveis elevados.

Média e desvio padrão de gasto na FDL na sDC: os gastos na subfunção indicam que a agenda também é valorizada, não só em termos de adesão. Os gastos no Paraná apontam com precisão uma possível distinção entre adesão e gasto. Apesar de ter menor adesão, apresentou maior gasto. Para todos os cenários, a preferência alocativa dos municípios é pelo gasto no esporte participação.

Evolução do gasto na sDC: a evolução do gasto demonstra que a agenda foi valorizada ao longo do período e obteve ganhos acima da inflação.

Descentralização top-down e bottom-up: os resultados aqui encontrados indicam uma das engrenagens do federalismo, atuação de mais de um ente federado dentro de um município. Os dados apontam também que, em se tratando de esporte participação, os governos municipais são os principais financiadores desta agenda na região.

Os dados gerais revelam intensa atividade política na região em torno da agenda do esporte e do lazer. Apesar dos incentivos à inação do federalismo brasileiro no que concerne à agenda esportiva, os resultados apontam em outra direção. Mesmo sem regulação federal, os municípios têm realizado importantes investimentos nas políticas públicas de esporte. No entanto, é importante salientar que desconhecemos as variáveis que ajudaram a moldar essa realidade. Nesse sentido, os resultados aqui apresentados abrem uma janela de estudos que não só devem identificar as variáveis intervenientes como aquelas que garantem relação causal com a adesão e com o gasto.

Outros dois fatores importantes que precisam de atenção futura são a apresentação dos resultados em outras subfunções, especialmente no Desporto Rendimento, e o acompanhamento dos resultados numa escala temporal mais alargada, como 15 ou 20 anos.

\section{REFERÊNCIAS}

ARRETCHE, Marta. Mitos da descentralização: mais democracia e eficiência nas políticas públicas. Revista Brasileira de Ciências Sociais, v. 11, n. 31, p. 44-66, 1996. 
ATHAYDE, Pedro Fernando Avalone. A disputa pelo fundo público no âmbito do financiamento esportivo brasileiro. Revista Brasileira de Ciências do Esporte, v. 36, n. 2, p. 636-651, 2016.

ATHAYDE, Pedro Fernando Avalone; MASCARENHAS, Fernando; SALVADOR, Evilásio.

Primeiras aproximações de uma análise do financiamento da política nacional de esporte e lazer no Governo Lula. Revista Brasileira de Ciências do Esporte, v. 37, n. 1, p. 2-10, 2015.

ATHAYDE, Pedro Fernando Avalone et al. Panorama sobre a constitucionalização do direito ao esporte no Brasil. Motrivivência, v. 28, n. 49, p. 38-53, 2016.

BERNARDI, Bruno Boti. O conceito de dependência da trajetória (path dependence): definições e controvérsias teóricas. Perspectivas: Revista de Ciências Sociais, v. 41, p. 137-167, 2012.

BODSTEIN, Regina. Atenção básica na agenda da saúde. Ciência \& Saúde Coletiva, v. 7, n. 3, p. 401-413, 2002.

BRASIL. Constituição. Constituição da República Federativa do Brasil. Brasília, DF: Senado Federal: Centro Gráfico, 1988.

BRASIL. Ministério do Planejamento, Orçamento e Gestão. Portaria n.. 42, de 14 de abril de 1999. Diário Oficial [da] República Federativa do Brasil, Brasília, DF, 14 abr. 1999. Disponível em: ftp://ttp.fnde.gov.br/web/siope/leis/P42 MPOG 14-041999.pdf. Acesso em: 20 fev. 2018.

BRASIL. Lei n. 4.320, de 17 de março de 1964: estatui normas gerais de direito financeiro para elaboração e controle dos orçamentos e balanços da união, dos estados, dos municípios e do Distrito Federal: Legislação complementar: Índice remissivo. Atlas, 2003.

CARNEIRO, Fernando Henrique Silva. 0 financiamento do esporte no Brasil: aspectos da atuação estatal nos governos Lula e Dilma. 2018. 385 f. Tese (Doutorado em Educação Física) Faculdade de Educação Física, UnB, Brasília, 2018.

CASTRO, Suélen Barboza Eiras. Políticas Públicas para o Esporte e Lazer e o Ciclo Orçamentário Brasileiro (2004-2011): Prioridades e Distribuição de Recursos Durante os Processos de Elaboração e Execução Orçamentária. Licere, v. 19, n. 3, p. 387-388, 2016.

CASTRO, Suélen Barboza Eiras; POFFO, Bianca Natália; SOUZA, Doralice Lange.

Financiamento do esporte de rendimento no Brasil: programa "Brasil no Esporte de alto rendimento" (2004-2011). Revista Brasileira de Ciência e Movimento, v. 24, n. 3, p. 146-157, 2016.

CASTRO, Suélen Barboza Eiras; SCARPIN, Jorge Eduardo; SOUZA, Doralice Lange. Financiamento público e esporte educacional: uma análise do processo orçamentário do programa "Segundo Tempo" (2004-2011). Motrivivência, v. 29, n. 52, p. 136-156, 2017.

COSTA, Valeriano Mendes Ferreira. Federalismo e relações intergovernamentais: implicações para a reforma da educação no Brasil. Educação e Sociedade, v. 13, n. 112, p. 729-748, jul./ set. 2010.

DINIZ, Rafael Silva; SILVA, Luciano Pereira. O ICMS esportivo e o financiamento das políticas municipais de esporte em Minas Gerais. Movimento, v. 22, n. 4, p. 1223-1236, out./dez. 2016.

FIGUERÔA, Katiuscia Mello; MEZZADRI, Fernando Marinho; SILVA, Marcelo Moraes. Rio 2016 e os legados de esporte e lazer. Licere, n.3, v.17, p. 99-133, 2014. 
FURTADO, Sabrina. et al. O financiamento do esporte em Santa Catarina: o caso do Fundesporte nos anos de 2011 e 2012. Motrivivência, v. 28, n. 47, p. 145-159, maio 2016.

GRASSO, Rita Peloso; ISAYAMA, Hélder Ferreira. Financiamento e políticas públicas de esporte e lazer: uma análise da gestão no município de Santarém/PA (2005-2012). Revista Brasileira de Ciência e Movimento, v. 25, n. 1, p. 151-167, 2017.

IBGE - Instituto Brasileiro de Geografia e Estatística. Perfil dos Municípios Brasileiro. 2006. Disponível em: https://ww2.ibge.gov.br/home/estatistica/economia/perfilmunic/2006/default.shtm. Acesso em: 20 out. 2018.

MASCARENHAS, Fernando. O orçamento do esporte: aspectos da atuação estatal de FHC a Dilma. Revista Brasileira de Educação Física e Esporte, v. 30, n. 4, p. 963-980, 2016.

MORAES, Paulo Mateus et al. O Programa Segundo Tempo na região Centro-Oeste: continuidade e estrutura burocrática do esporte nos municípios. Revista Brasileira de Ciência e Movimento, v. 25, n. 1, p. 129-140, 2017.

REZENDE, Flávio da Cunha. Descentralização, gastos públicos e preferências alocativas dos governos locais no Brasil:(1980-1994). Dados, v. 40, n. 3, p. 441-467, 1997.

RIBEIRO, Leandro Molhano. Federalismo, governo local e políticas sociais no Brasil entre 1996 e 2004. In: HOCHMAN, Gilberto; FARIA, Carlos Aurélio Pimenta de. (orgs.) Federalismo e políticas públicas no Brasil. Rio de Janeiro: FIOCRUZ, 2013. p. 151-175.

SABATIER, Paulo. Top-down and bottom-up approaches to implementation research: a critical analysis and suggested synthesis. Journal of Public Policy, v. 6, n. 1, p. 21-48, 1986.

SANTOS, Edmilson Santos; STAREPRAVO, Fernando Augusto. Political-Administrative Structure of Municipal Governments in Piauí and Investment in Sport and Leisure. Licere, v. 21, p. 166-183, 2018.

SANTOS, Edmilson Santos; HIRATA, Edson. Investimento Na Função Desporto E Lazer Por Níveis de Índice de Desenvolvimento Humano. Caderno De Educação Física, v. 15, p. 49-55, 2017.

SILVA, Temistocles Damasceno; COUTO, Ana Marcela Santos; SANTOS, Mario Lucas Alves. Analysis of the administrative structure and financial sport in IPIAU-BA county. Podium: Sport, Leisure and Tourism Review, v. 3, n. 3, p. 77-88, 2014.

SILVA, Temístocles Damasceno; SANTANA, Tiago Almeida; SILVA, Ricardo Correia. O planejamento e a estrutura financeira das políticas públicas de lazer no estado da Bahia. Coleção Pesquisa em Educação Física, v. 14, n. 04, p. 121-130, 2015.

SOUZA, Celina. Políticas públicas: uma revisão da literatura. Sociologias, ano 8, n. 16, p. 20 45, jul./dez. 2006

VAZ, Alexandre Fernandez. Políticas públicas para o esporte e o lazer em Santa Catarina: reflexões e considerações. Journal of Physical Education, v. 12, n. 1, p. 89-96, 2001.

VENTURIM, Lorenza Falchetto; BORGES Carlos Nazareno Ferreira; SILVA, Dirceu Santos. Estratégias de gestão pública na prefeitura de Vitória/ES? O PELC e a intersetorialidade das ações. Licere, v. 16, n. 4, p. 1-38, dez. 2013. 
VERONEZ Luiz Fernando C. Quando o Estado joga a favor do privado: as políticas de esporte após a Constituição Federal de 1988. 386 f. Tese (Doutorado em Educação Física) Faculdade de Educação Física, Unicamp, Campinas, 2005. 